\title{
Determination of hydrological roughness by means of close range remote sensing
}

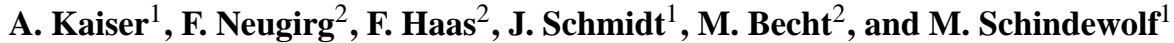 \\ ${ }^{1}$ Technical University Bergakademie Freiberg, Germany \\ ${ }^{2}$ Catholic University Eichstätt-Ingolstadt, Germany \\ Correspondence to: A. Kaiser (andreas.kaiser@tbt.tu-freiberg.de) and F. Neugirg (f.neugirg@ku.de) \\ Received: 2 April 2015 - Published in SOIL Discuss.: 8 May 2015 \\ Accepted: 1 September 2015 - Published: 14 September 2015
}

\begin{abstract}
The objective of the presented work was to develop a method to acquire Manning's $n$ by creating very high-resolution surface models with structure-from-motion methods. As hydraulic roughness is an essential parameter for physically based erosion models, a practical measuring technique is valuable during field work. Data acquisition took place during several field experiments in the Lainbach valley, southern Germany, and on agricultural sites in Saxony, eastern Germany, and in central Brazil. Rill and interrill conditions were simulated by flow experiments. In order to validate our findings stream velocity was measured with colour tracers. Grain sizes were derived by measuring distances from a best fit line to the reconstructed soil surface. Several diameters from $D_{50}$ to $D_{90}$ were tested with $D_{90}$ showing best correlation between tracer experiments and photogrammetrically acquired data. Several roughness parameters were tested (standard deviation, random roughness, Garbrecht's $n$ and $\left.D_{90}\right)$. Best agreement in between the grain size and the hydraulic roughness was achieved with a non-linear sigmoid function and $D_{90}$ rather than with the Garbrecht equation or statistical parameters.
\end{abstract}

Abbreviations

\begin{tabular}{ll}
\hline DEM & $\begin{array}{l}\text { digital elevation model } \\
\text { digital elevation model } \\
\text { of difference }\end{array}$ \\
DSLR & $\begin{array}{l}\text { digital single-lens reflex camera } \\
\text { erosion 3-D soil erosion model }\end{array}$ \\
E3D & geographic information system \\
GIS & ground sampling distance \\
GSD & light detection and ranging \\
lidar & Limburg Soil Erosion Model \\
LISEM & Profile Meter Program \\
PMP & root mean squared error \\
RMSEP & of prediction \\
& random roughness \\
RR & standard deviation \\
SD & structure from motion \\
SfM & Water Erosion Prediction Project \\
WEPP &
\end{tabular}

\section{Introduction}

Hydraulic parameters are essential factors in erosion research with surface roughness being a crucial one. A variety of studies repeatedly analysed roughness from different approaches on different scales: Borselli and Torri (2010) looked at the interaction between slope, surface roughness and storage abilities in their storage cup and storage empirical models. Their experiments showed that best performance was achieved with rather simple statistical parameters like random roughness or the Abbot-Firestone curve (Abbott and Firestone, 1933) in comparison to more complex fractal indices or geostatistical approaches (Borselli and Torri, 2010). Smith et al. (2004) worked on a larger scale with airborne lidar and photogrammetry data to improve the quality of hydrodynamic flow prediction for flooding areas by applying classified Manning's $n$ values on the produced DEMs (Smith et al., 2004). A C-band radar evaluation for determining surface roughness was carried out by Rahman et al. (2008) using satellite data from Envisat and validating them with pin meter measurements. Zheng et al. (2012) published a study 
closely related to our work as they compared soil surface roughness with a hydraulic roughness coefficient. They derived functions to relate the Manning's $n$ to the measured surface roughness and could thus achieve good coefficients of determination $\left(R^{2}=0.89\right)$ for different slope gradients on loessic soils. Nonetheless, the range of different grain sizes and thus surface roughness is restricted to one soil type and the measurement was carried out using a pin meter (Zheng et al., 2012). The latter is a useful tool for random roughness measurements and has also been applied in older studies for determining surface roughness values. A study by Cremers et al. (1996) developed a semi-photographic approach by capturing images of the pins for the PMP which then calculates surface heights (Cremers et al., 1996).

The interaction between hydrological roughness and slope is of major influence on stream velocity. Besides the storage capacities of a rough surface, these vectored characteristics of flow play an important role in the initial conditions for soil detachment. Physically based soil erosion models are reliant on field experiments to generate data for running the model. One crucial influence factor is stream velocity $v$ as it interacts with parameters such as liquid density or volume flow to calculate further physical values. Shear stress $\tau$ and thus shear rate $\gamma$, stream power $\omega$ and the Reynolds number $R e$ are affected by stream velocity $v$ whereas the stream velocity is mainly steered by slope and roughness. While there are several possible methods to acquire information on slope, roughness as function of the hydraulic resistance of the soil surface represents a tricky parameter when it comes to measuring methods. Nevertheless, the Manning's roughness coefficient $n$ is a crucial parameter for physically based soil erosion models such as LISEM (de Roo and Wesseling, 1996), WEPP (Laflen et al., 1991) and E3D (Schmidt, 1991) and thus is mandatory to be measured in situ. As a consequence of the high complexity of surfaces in rill and interrill areas, a direct approach to acquiring roughness values is hardly feasible. However, advancing technologies and decreasing computing times enable new approaches to surface reconstruction. The presented study applies SfM algorithms to produce high-resolution surface models to derive information on microtopography, which influences the runoff.

Up to now, the required roughness values were determined in laborious flow experiments as described in the methods section of this study. These are limited with regard to the covered surface and the number of possible runs. Furthermore, the position of the plot is chosen according to the accessibility and is thus restricted and not free of subjectivity. Therefore, the overall aim of this study is to test the relationship between a very high-resolution topography model and the measured hydraulic roughness values. Common roughness coefficients were tested for their applicability with Garbrecht's $D_{90}$ showing best correlations. Additionally, the study provides preliminary results for raster-based soil erosion models as new possibilities in surface reconstruction arise and can be of high value for model application.

\section{Methodology}

\subsection{Research area}

It is important to note that the main motivation for the selection of the research areas was not the presented study itself, as it was not dependent on site-specific differences like climate or substrate. Instead, the experimental data resulted from adaptations of a larger measuring setup for rainfall simulations and were thus generated as a by-product.

\subsubsection{Lainbach valley, Bavaria, Germany}

Being object to many research projects in several geoscientific disciplines (Banasik and Bley, 1994; Bunza et al., 2004; Grottenthaler and Laatsch, 1973; de Jong, 1995; Schmidt, 1994; Wetzel, 2003) the Lainbach valley in the Northern Limestone Alps $\left(47^{\circ} 40^{\prime} 35^{\prime \prime} \mathrm{N}\right.$ and $\left.11^{\circ} 27^{\prime} 35^{\prime \prime} \mathrm{E}\right)$ was chosen for the field experiments. Altitudes in the $18.4 \mathrm{~km}^{2}$ catchment range from $1801 \mathrm{~m}$ at the Benediktenwand to around $700 \mathrm{~m}$ at the outlet of the river Lainbach close to the city of Benediktbeuern. Underlain mainly by flysch the basin is filled with Pleistocene glacial moraine deposits which reveal high morphodynamics on unvegetated slopes (Becht, 1989; Kaiser et al., 2015). These slopes deliver major quantities of sediment to the river network especially during heavy rain events. Freeze-thaw cycles trigger mudflows and thus provide additional material for erosion processes. Neugirg et al. (2014) applied a terrestrial lidar monitoring to measure a mean annual denudation rate of $3.4 \mathrm{~cm}$ on a slope in the Melcherreiße, an active slope in the headwaters of the Lainbach valley (Neugirg et al., 2014). Data for the study at hand were also collected at the Melcherreiße due to reasonable accessibility and already existing field data from former campaigns including a rainfall simulation (Kaiser et al., 2015). An inclination of around $40^{\circ}$ at the experimental sites was found to be appropriate with regard to the typical slope gradient in the active areas of the Lainbach valley.

\subsubsection{Heidenau and Zwönitz, Saxony, Germany}

Two additional experimental sites are located within the federal state of Saxony. Three main landscapes characterize Saxony: lowlands in the north, hilly uplands in the centre and the Erzgebirge mountain range in the south. The mean annual rainfall lies between $700 \mathrm{~mm}$ in the lowlands and up to $1000 \mathrm{~mm}$ in higher regions. One of the research sites close to the village of Heidenau is located on ploughed Loessic Luvisols with remaining stubble from previous year's corn. Soil texture shows a sandy silt opposing to the Zwönitz site with a higher clay content resulting in a silty loam. While Heidenau $\left(50^{\circ} 57^{\prime} 13^{\prime \prime} \mathrm{N}\right.$ and $\left.13^{\circ} 52^{\prime} 23^{\prime \prime} \mathrm{E}\right)$ is underlain by glacial deposits from Saalian Stage the Zwönitz experimental area is situated on metamorphic bedrock. Comparable to Heidenau the field was also left with corn stubble. The soil type 
was classified as a Podzolic Cambisol. Different tillage measures were applied to the test plots: intensive non-invasive mulching, strip-till and no-till.

\subsubsection{Novo Progresso, Pará, Brazil}

In Novo Progresso the study areas are located in the Amazonian lowlands with a humid tropical climate of $2232 \mathrm{~mm}$ per year and $25^{\circ} \mathrm{C}$ mean temperature at $07^{\circ} 07^{\prime} 33^{\prime \prime} \mathrm{S}$ and $55^{\circ} 25^{\prime} 58^{\prime \prime} \mathrm{W}$. Within the corridor around the BR 163 and minor roads forest is intensively logged, while deforested land is used as pasture. Mostly gleyic, Haplic Acrisols and fewer Ferralsols are found and dominant in the area. Since pastures are degrading very rapidly, deep ploughing serves as an appropriate measure to remove soil compaction, as it was applied to both plots.

\subsection{Discharge experiments}

In the experimental setup we used colour tracer to measure flow velocities and thus derive hydraulic roughness values applying Manning's equation. The latter was chosen as it is a widespread formula and associated with a large quantity of existing data. Furthermore, a work on overland flow by Emmett (1970) states that the Manning's equation serves adequately to estimate flow properties of turbulent flow. In a next step these values were compared to surface roughness data produced with SfM models. Algorithms were designed in $\mathrm{R}$ to approximate both roughness measurements e.g. by considering the flow direction in the surface roughness. In a last step the gained data served as model input for the physically based soil erosion model E3D in order to evaluate the results for modelling applications, which again supports the usage of Manning's equation The model output is then compared to actual detachment acquired from DoDs from the before and after imagery from the experimental plots.

For data acquisition, discharge experiments on a $1 \times 1 \mathrm{~m}^{2}$ plot were carried out on steep slopes in the Lainbach catchment (Fig. 1). A 30 L barrel supplied the plot for around 3 min with runoff, which was introduced to the soil surface via a distributor to achieve comparable layer thickness at the upper end of the plot. The chosen amount of water per second corresponded to a simulated slope length of $>10 \mathrm{~m}$ in a frequently applied experimental setup (Schindewolf and Schmidt, 2012). Additionally, all runoff was collected through a pipe and measuring cups at the outlet including sediment samples for determining erosion rates and the soils resistance to erosion. The latter is a crucial input for the erosion model E3D and is determined as

$\varphi_{\text {crit }}=\frac{q_{\text {crit }} \cdot \rho_{q} \cdot v_{q}}{\Delta_{x}}$

with $q_{\text {crit }}$ being the volume rate of discharge $\left(\mathrm{m}^{3}(\mathrm{~m} \mathrm{~s})^{-1}\right)$, the fluid density as $\rho_{q}\left(\mathrm{~kg} \mathrm{~m}^{-1}\right)$, flow velocity $v_{q}\left(\mathrm{~m} \mathrm{~s}^{-1}\right)$ and $\Delta_{x}$ as the slope width (m), which in our case is $1 \mathrm{~m}$.
Demonstrated above, flow velocity influences soil detachment and is again dependent on surface roughness as shown in the following equation after Manning:

$v_{q}=\frac{1}{n} \delta^{\frac{2}{3}} \cdot S^{\frac{1}{2}}$.

Hydraulic surface roughness is given by $n\left(\mathrm{~s} \mathrm{~m}^{-1 / 3}\right), S$ is slope $\left(\mathrm{m} \mathrm{m}^{-1}\right)$ and $\delta$ the depth of flow (m). Equation (2) already is an alteration of the original Manning equation as the hydraulic radius $R$ was replaced by the flow depth. The reason for the replacement of the hydraulic radius with the flow depth lies in predominant sheet flow conditions on our research plots. While the hydraulic radius is an important factor in channel flow it can be approximated to the flow depth in the case of our experiments as it is described as the product of flow depth and flow cross section. In this regard flow depth is a product of the continuity equation as a mean value for the entire plot. As a function of flow volume $q$ and flow velocity $v$ it can be described as follows when inserted in Eq. (2):

$\delta=\left(\frac{q \cdot n}{S^{\frac{1}{2}}}\right)^{\frac{3}{5}}$.

The hydraulic surface roughness can thus be calculated by solving the Manning equation for $n$ :

$n=v_{q}^{-\frac{5}{3}} \cdot q^{\frac{2}{3}} \cdot S^{\frac{1}{2}}$.

Flow velocity as a variable of Eq. (4) was measured in the above described setup by adding colour tracer (Vitasyn Blue AE 90) to the flow. Due to concentrating flow on the plot a difference in velocity was evident. To later differentiate between fast and slow flow areas and to validate flow velocities, two cameras were installed to videotape the discharge experiments at 60 frames per second from different angles.

\subsection{Structure from motion and data preparation}

The input data for the surface reconstruction consists of a multitude of short-range images from different perspectives of the measured surface. They were acquired before and after the experiment. Then applied SfM procedures allow for a straightforward workflow and accurate elevation data (Lowe, 1999; James and Robson, 2012; Kaiser et al., 2014). Image positions were more or less randomized with a focus on total coverage resulting in around 30 images per plot. Internal camera parameters were not changed throughout the experiment. The chosen camera was a Canon EOS 6D full format DSLR with a Tokina $16-28 \mathrm{~mm} f / 2.8$ lens locked at $16 \mathrm{~mm}$ and $f / 8.0$. The lens was picked due to a decent closest focusing distance and high sharpness. However, a lens calibration due to the wide angle distortion of a full format sensor without crop factor was carried out in Agisoft Lens to increase precision (Agisoft, 2014a). Point densities of $\approx 5700$ per $\mathrm{cm}^{2}$ allowed for a very accurate surface representation 


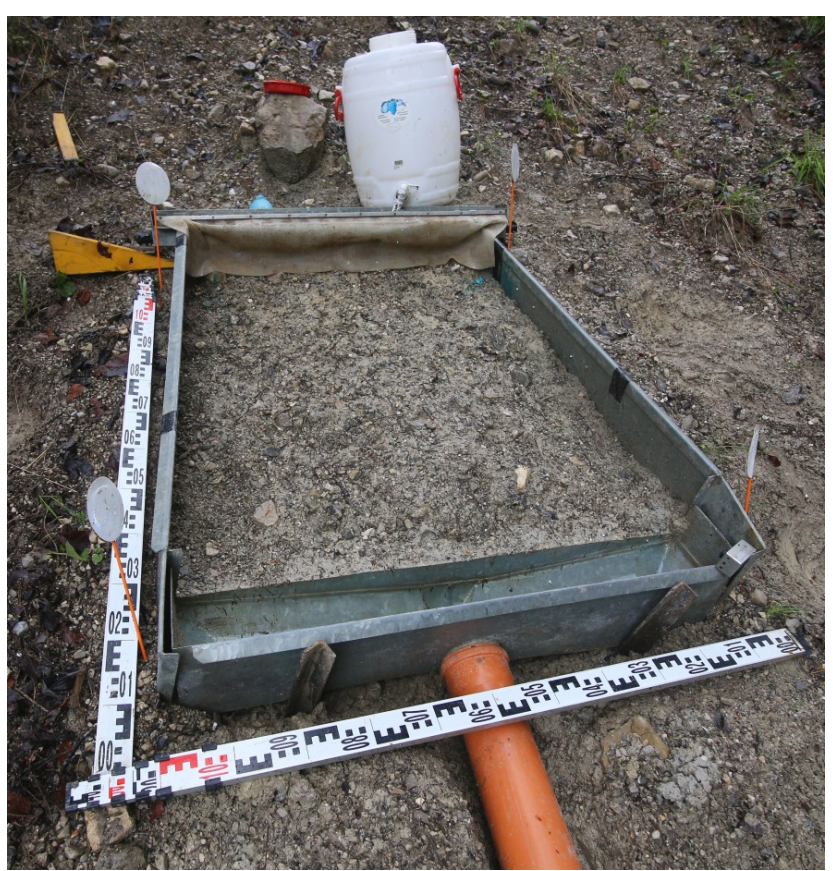

Figure 1. Experimental setup including plot, $30 \mathrm{~L}$ barrel, runoff collector, reflectors for tachymeter registration and measuring stick for scaling purposes.

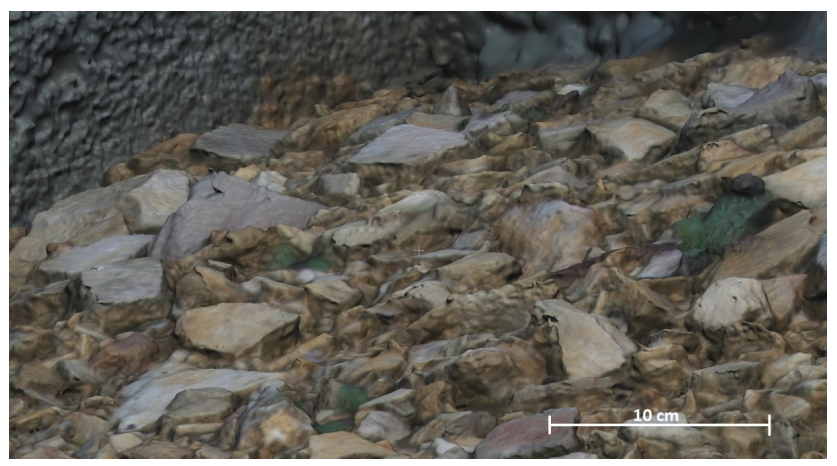

Figure 2. Detail of the surface model with 57 million points. The rough surface of the metal plot border results from its flat surface which impedes feature detection for SfM.

and are a result of the low GSD of $0.01625 \mathrm{~mm}$ if we assume a distance of $40 \mathrm{~cm}$ from camera to plot surface (Fig. 2).

To achieve correct scaling and orientation of the 3-D models we placed four tie points serving as ground control points at each corner of the plot which were then measured with a Leica TPS1200/TCRM1205 tachymeter for later $x y z$ registration. After the referencing to a local coordinate system in Agisoft PhotoScan (Agisoft, 2014b) all point clouds needed to be subsampled to achieve similar point densities throughout the plot. Different point distances from $0.01,1$ and $10 \mathrm{~mm}$ were chosen to find an adequate compromise between resolution and fluent data treatment. Secondly, the point clouds were gridded to a $1 \mathrm{~mm}$ DEM for GIS analysis in SAGA GIS

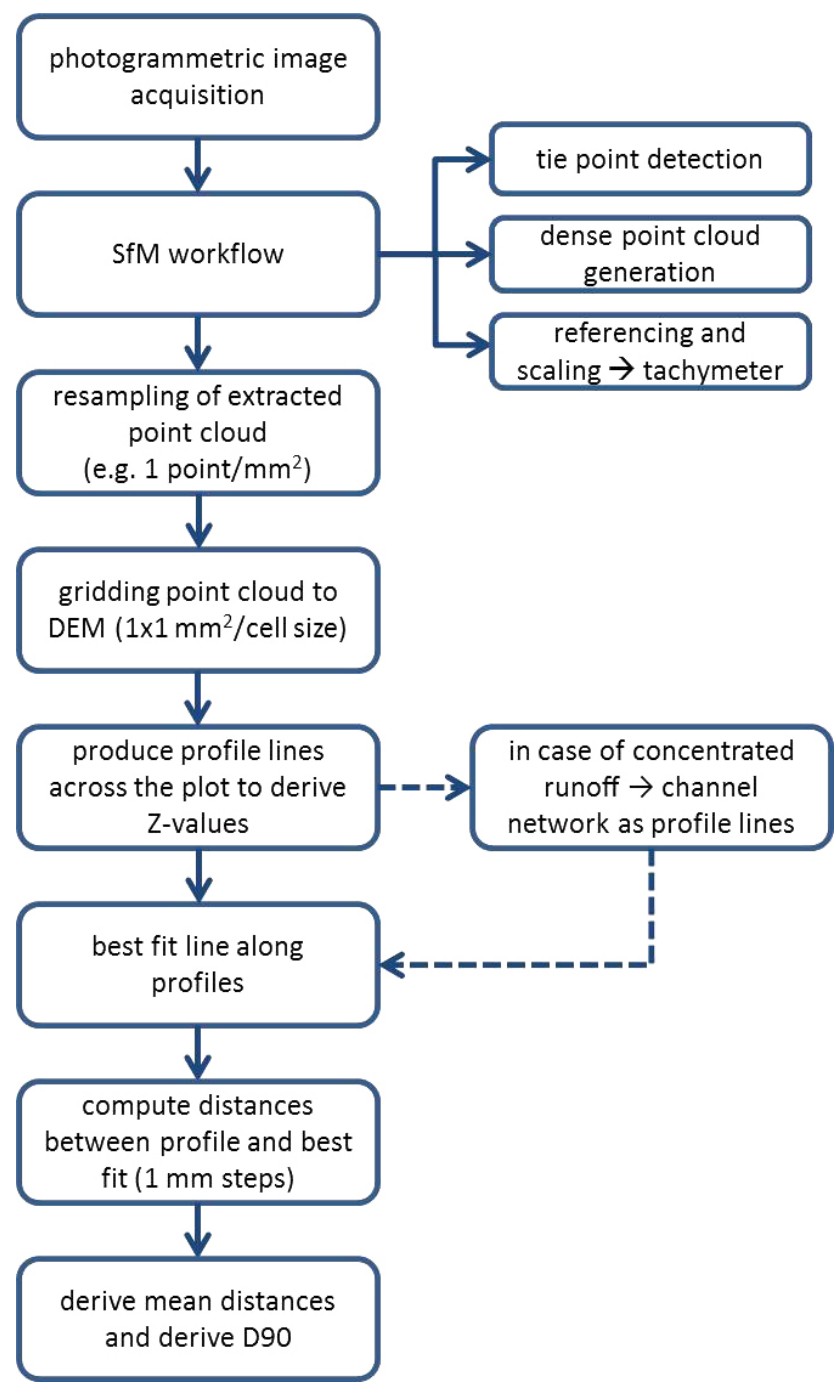

Figure 3. Workflow from image acquisition to roughness values. The dotted branch shows the possibility to implement depression lines derived from the channel network in SAGA GIS in case of concentrated rill flow.

using a point cloud to raster function. The above described procedure is shown in Fig. 3 and was carried out for all plots under before and after experiment conditions.

\subsection{Deriving roughness values}

Several approaches were tested before a considerable correlation between measured Manning $n$ values and the DEMbased roughness was detected. All of the trials are explained and evaluated in the discussion section. The here described procedure led to the best relationship of surface roughness values derived from the DEM and Manning's $n$ measured with flow experiments.

For obtaining elevation values from the DEMs eight profile lines along the flow direction were created in SAGA GIS 


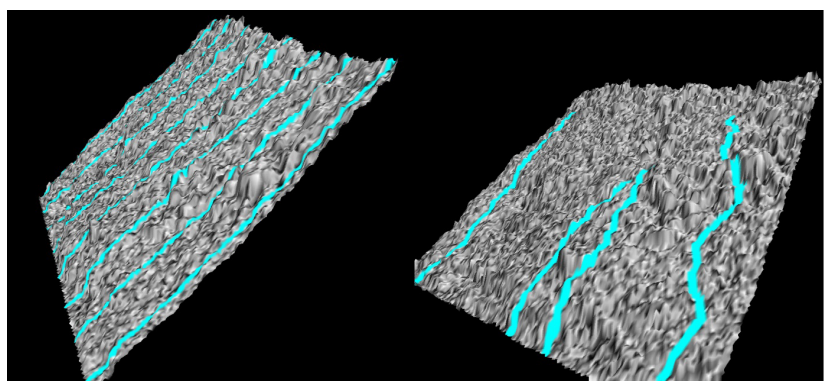

Figure 4. Profile lines across the DEM. Straight lines (left) and channel flow (right) are chosen dependent on the prevalent runoff type.

while all further analysis was carried out in R ( R Development Core Team, 2008). These profile lines represent so to speak the digital equivalent to the results of profiler measurements (de Jong, 1995; Nikora et al., 1998). A best fit line was plotted through each profile to collect data on the deviation from profile line to its best fit line as an approximation of roughness (Fig. 4).

In a next step basic roughness parameters like the SD and RR were tested. Additionally, the positive residues above the line were measured perpendicular to the best fit line and the $D_{90}$ values across all profile lines were derived for every plot. The $D_{90}$ represents the grain size at which the diameters of $90 \%$ of all particles are finer than. In brief, the resulting values represent the mean $D_{90}$ values from eight profile lines for each plot. These values then serve as the input for the empirical formula of Garbrecht to determine $n$ (Garbrecht, 1961):

$n=\frac{D_{90^{\frac{1}{6}}}}{26}$

with $D$ being the diameter under which a certain percentage (e.g. 90) of all particles is to be found. These $n$ values are then compared to the results from Eq. (4) and accordingly the tracer experiments for measuring flow velocity. One experimental site produced strong rill flow and thus outliers. These were corrected by extracting the depression line in GIS via flow accumulation as a profile line rather than a random straight line across the plot from top to bottom. Nevertheless, the latter was suitable for the other plots that showed higher rates of sheet flow.

\section{Results}

Table 1 gives an overview of the measured values from a total of 21 experiments. In a few cases slope remains stable as one plot was used for several flow simulations. A resulting example for a profile line derived from the high-resolution surface models is shown in Fig. 5. Clearly visible are areas of high and low flow resistance respectively of flat and more

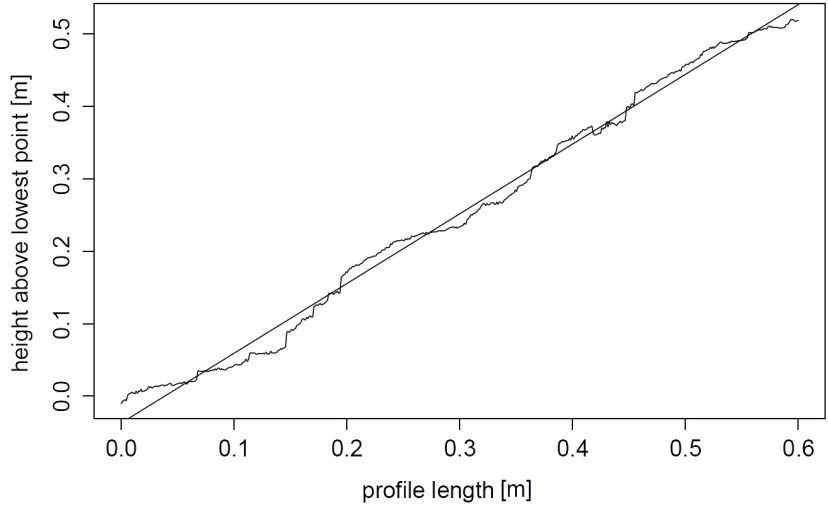

Figure 5. Exemplary profile line for a plot in the Lainbach valley showing the derived soil surface and the inserted best fit line.

Table 1. Hydrological parameters ( $n$ Manning, flow velocity, slope and discharge) measured during the experiments for all research sites. Values P1 to P4 were acquired in the Lainbach valley. Hn and $\mathrm{Zw}$ are the ones from Saxony, and Flo1 was measured in Brazil.

\begin{tabular}{lcccc}
\hline & $n$ Manning & $v\left(\mathrm{~m} \mathrm{~s}^{-1}\right)$ & $S\left(\mathrm{~m} \mathrm{~m}^{-1}\right)$ & $Q\left(\mathrm{~mL} \mathrm{~s}^{-1}\right)$ \\
\hline P1_v & 0.043 & 0.13 & 0.54 & 0.08 \\
P1_m & 0.046 & 0.12 & 0.54 & 0.08 \\
P1_n & 0.028 & 0.14 & 0.54 & 0.05 \\
P2_v & 0.071 & 0.09 & 0.67 & 0.05 \\
P2_m & 0.056 & 0.10 & 0.67 & 0.05 \\
P2_n & 0.036 & 0.17 & 0.67 & 0.10 \\
P3_v & 0.032 & 0.19 & 0.67 & 0.12 \\
P3_m & 0.022 & 0.26 & 0.67 & 0.12 \\
P3_n & 0.016 & 0.33 & 0.67 & 0.16 \\
P4_v & 0.072 & 0.12 & 0.83 & 0.11 \\
P4_m1 & 0.013 & 0.34 & 0.83 & 0.11 \\
P4_m2 & 0.019 & 0.28 & 0.83 & 0.12 \\
P4_n & 0.018 & 0.30 & 0.83 & 0.14 \\
Hn1 & 0.011 & 0.22 & 0.1 & 0.13 \\
Hn2 & 0.011 & 0.23 & 0.1 & 0.15 \\
Hn3 & 0.016 & 0.17 & 0.13 & 0.15 \\
Hn4 & 0.011 & 0.24 & 0.09 & 0.15 \\
Hn5 & 0.077 & 0.07 & 0.12 & 0.12 \\
Hn6 & 0.056 & 0.08 & 0.09 & 0.14 \\
Zw4 & 0.025 & 0.13 & 0.09 & 0.14 \\
Flo1 & 0.109 & 0.07 & 0.07 & 0.34 \\
\hline
\end{tabular}

complex surface structures. Furthermore, areas with little inclination alternate with steep sections.

Table 2 summarizes the comparison of tested correlations between different parameters for describing roughness. Representing simple statistical analyses, both the roughness SD and RR perform not as well as the Garbrecht equation in $R^{2}$. Additionally, the root mean square error of prediction was tested as a more suitable measure in view of the fact that the data serve as input for a physically based soil erosion model. In both cases (SD and RR) their predictive power is better than the one of the Garbrecht equation. However, best 
Table 2. Comparison of different roughness parameters and their coefficients of determination and RMSEP with Manning's $n$ (hydraulic roughness).

\begin{tabular}{lcc}
\hline & $R^{2}$ & RMSEP \\
\hline SD vs. Manning $n$ & 0.33 & 0.0235 \\
RR vs. Manning $n$ & 0.42 & 0.0191 \\
Garbrecht $n$ vs. Manning $n$ & 0.78 & 0.0945 \\
$D_{90}$ vs. Manning $n$ & 0.89 & 0.0085 \\
\hline
\end{tabular}

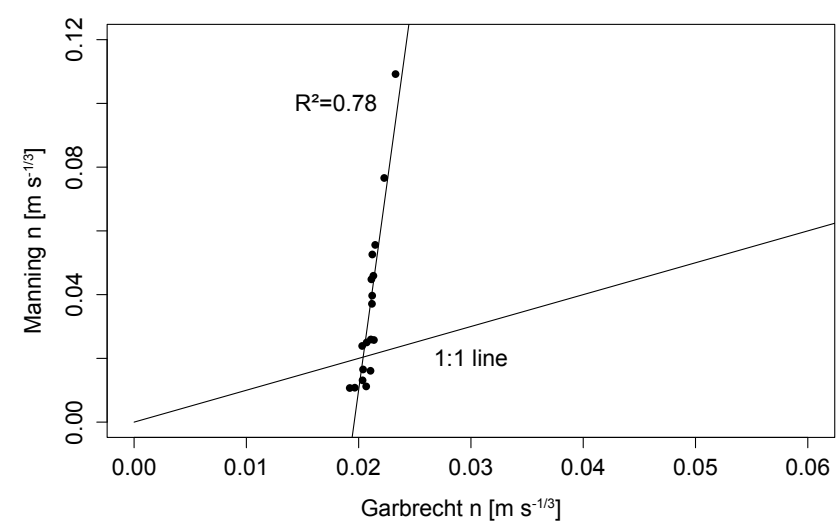

Figure 6. Linear regression of the Garbrecht $n$ values in comparison to the $1: 1$ line representing the best prediction for the model parameters.

agreement is found between $D_{90}$ and the Manning hydraulic roughness. Figure 6 explains this with good linear correlation among the values but a variance in slope to the $1: 1$ line representing best predictive accuracy.

\section{Discussion}

Several roughness parameters show an average correlation during curve fitting (Table 2). Random roughness performs adequately with $R^{2}=0.42$. Furthermore, an acceptable agreement of this study $\left(R^{2}=0.78\right)$ and a comparable one by Michael (2000) $\left(R^{2}=0.76\right)$ between the Garbrecht equation (Eq. 5) and Manning (Eq. 4) prove the applicability of Garbrecht for describing roughness values (Michael, 2000). Nevertheless, in our value range the predictive accuracy is not satisfying as can be seen in Fig. 6, especially as our study is looking at modelling parameters for a physically based erosion model. The study by Michael (2000), in which particles were collected from the soil surface for later laboratory grain size analyses, differs from the here shown photogrammetric approach but does not influence the above explained results. While Garbrecht produces plausible values for channel and stream roughness it seems less accurate for shallow sheet flow as in the presented study. Comparing only the different grain sizes from $D_{50}$ to $D_{90}$ led to the assumption that $D_{90}$ performs best in a linear correlation with

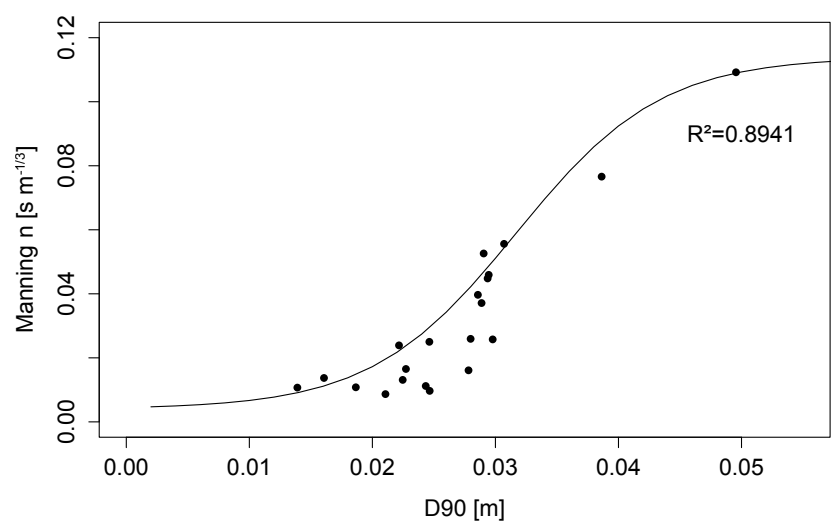

Figure 7. Comparison of $D_{90}$ values derived from SfM data and the Manning's $n$ resulting from tracer experiments. A sigmoid function distinctly increases the coefficient of determination.

Manning's $n$ but nevertheless does not correlate satisfyingly (Table 3).

Consequently, a more suitable description than Garbrecht's $n$ and a linear regression for the high-resolution surface data correlated to hydraulic roughness is required. Better performance for the agreement of Manning's $n$ and the $D_{90}$ values was achieved with a logistic function and accordingly a sigmoid curve (Fig. 7). This led to the assumption that the behaviour of the curve at the lower end of Manning $n$ values can be described by an overshooting of runoff of small-scale gaps between particles without causing measurable disturbance and accordingly deceleration to the fluid. This is expected to occur on sealed soil surfaces in deposition areas of clay and fine silt.

Larger particles produce stronger disturbance to the flow, which is represented by a rise of the graph to a certain level. This level is reached due to a rather low value of layer thickness of the surface runoff, which is accountable for a second turning point in the curve as the influence of grain sizes decreases. In our experiments with roughly $0.25 \mathrm{~L} \mathrm{~m} \mathrm{~s}^{-1}$ we do not exceed a certain flow depth, which again is repeatedly exceeded by grain sizes on the plot. In our case this value lies in the range of approx. $5 \mathrm{~cm}$. The highest flow depths occur on the lower part of the plot in concentrated rill runoff, but still the water flows around the larger obstacles rather than overflowing them. All grain sizes above this critical level protrude the water surface and no longer influence Manning's $n$, which leads to a levelling of the curve as they increase the $D_{90}$ value while Manning's $n$ remains stable.

Figure 8 shows the sensitivities of the normalized input parameters for Manning's $n$. The Manning equation was parameterized with the mean values of our measurements. Percentage changes of the independent variable (input) on the $x$ axis are plotted against percentage changes of Manning's $n$ on the $y$ axis. The intercept of the grey lines shows the average values of our measurements. Flow velocity, as the most sensitive parameter of the equation represented by the 


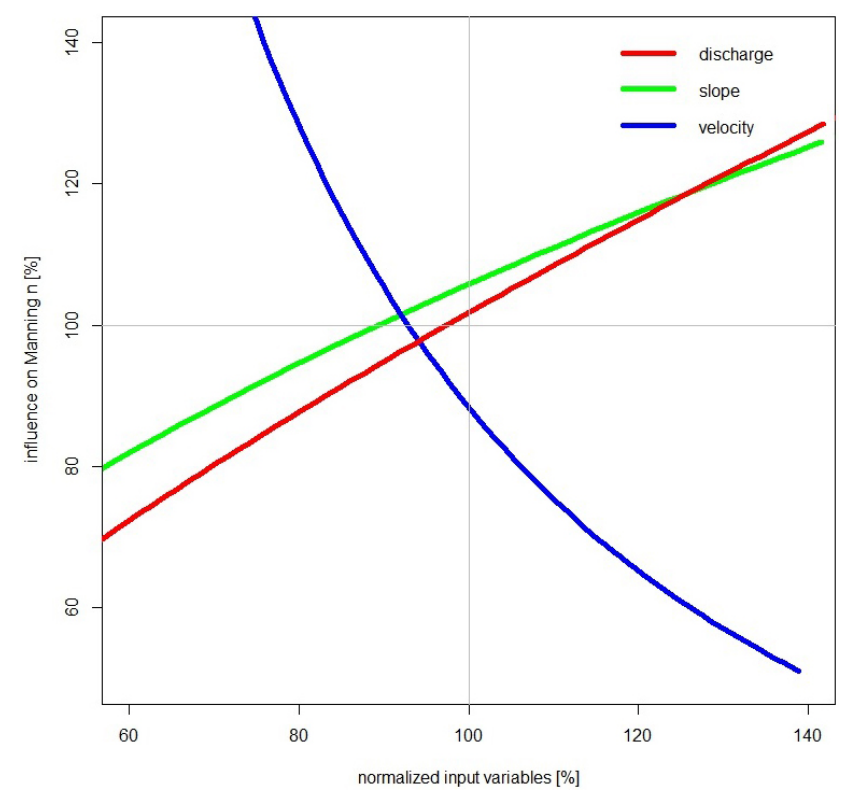

Figure 8. Sensitivity of three normalized input parameters and their influence on Manning's $n$.

blue line, shows a steep decline of high Manning $n$ for low flow velocities but flattens for high velocities. This shows a rather low sensitivity for higher (and challenging to measure) discharge velocities, whilst measuring mistakes in the lower region result in larger discrepancies for $n$. The graphs for slope and discharge both show proportional behaviour: an increase in discharge requires an increase in roughness if velocity and slope remain stable. Several statistical parameters were tested before achieving the above results. Standard deviation representing surface roughness was calculated by distances from points to a best fit plane. All points within a certain search radius are analysed concerning their $z$ values. The standard deviation of all $z$ values is the roughness value for the point in the centre of the search radius. The analysis was carried out using the module "Surface Roughness" in SAGA GIS, which works point cloud based. In a different approach we tested all residues from the best fit line - positive and negative. As described in the methods section only the positive residues above the best fit line were followed up on. The reason for this is that correlation with the hydraulic roughness decreased in all cases when including the negative residues. An explanation could be given by the fact that the distances were calculated perpendicularly, and thus originally flat areas of low flow resistance act as ascent when the profile is levelled. On the other hand, also a distance measurement profile to best fit line without a levelling of both did not produce decent results either.
Table 3. Linear regression between different grain sizes and Manning's $n$.

\begin{tabular}{ll}
\hline Diameter & $R^{2}$ \\
\hline$D_{50}$ & 0.1046 \\
$D_{60}$ & 0.1333 \\
$D_{70}$ & 0.1577 \\
$D_{80}$ & 0.1688 \\
$D_{90}$ & 0.4491 \\
\hline
\end{tabular}

\section{Conclusion and outlook}

The results of the comparison between surface roughness data generated with a SfM workflow showed good agreement with measured hydraulic roughness coefficients. Nevertheless, for definite statements about the overall correlation and operability of the suggested method a wider range of data is required. Here presented measurements rather serve as a preliminary overview of an application of high-resolution topography but need to be statistically strengthened. Especially larger $D_{90}$ values in combination with higher flow depth would reasonably expand the data set to allow a validation of the sigmoid function. Another way forward would include unaltered flow depths but significantly rougher surfaces to test their alignment with the upper plateau of the sigmoid function to prove the hypothesis that larger particles cannot be overflown and thus no longer influence Manning's $n$. Further research should also focus on running a physically based erosion model with both the roughness values resulting from SfM measurements and the classic approach. This could then additionally be validated with soil loss data from multi-temporal laser scans. As hydraulic roughness, also referred to as oriented roughness (Cremers et al., 1996), has a vectored character which might lead to differences in hydraulic roughness dependent on the flow direction (e.g. from furrows caused by ploughing), further research should tackle this aspect by differentiating between obstacles on or a descent of the profile line.

Acknowledgements. The present study was only possible due to the financial support of the German Research Foundation (DFG grant numbers: HA5740/3-1, SCHM1373/8-1). Furthermore, the authors would like to thank Christian Böhm for his support during field work and parts of the initial data preparation.

Edited by: J. A. Gomez 


\section{References}

Abbott, E. J. and Firestone, F. A.: Specifying surface quality: a method based on accurate measurement and comparison, ASME Journal of Mechanical Engineering, 55, 569-572, 1933.

Agisoft: Lens: http://downloads.agisoft.ru/lens/doc/en/lens.pdf, last access: 10 May 2014.

Agisoft: PhotoScan: http://downloads.agisoft.ru/pdf/ photoscan-pro_1_0_0_en.pdf, last access: 12 May 2014.

Banasik, K. and Bley, D.: An attempt at modelling suspended sediment concentration after storm events in an Alpine torrent, Lecture Notes in Earth Sciences, 52, 161-170, 1994.

Becht, M.: Neue Erkenntnisse zur Entstehung pleistozäner Talverfüllungen, Eiszeitalter und Gegenwart, 39, 1-9, 1989.

Borselli, L. and Torri, D.: Soil roughness, slope and surface storage relationship for impervious areas, J. Hydrol., 393, 389-400, doi:10.1016/j.jhydrol.2010.09.002, 2010.

Bunza, G., Ploner, A., and Sönser, T.: Die Modellierung des Abfluss- und Feststofftransportes in Wildbächen für die Beurteilung und Planung von Schutzmassnahmen dargestellt am Beispiel des Lainbach bei Benediktbeuern, Bayern, Internationales Symposium INTERPRAEVENT 2004 - Riva, Trient, 6, 83-92, 2004.

Cremers, N. H., Van Dijk, P. M., de Roo A. P. J., and Verzandvoort, M. A.: Spatial and temporal variability of soil surface roughness and the application in hydrological and soil erosion modelling, Hydrol. Process., 1035-1047, 1996.

de Jong, C.: Temporal and spatial interactions between river bed roughness, geometry, bedload transport and flow hydraulics in mountain streams: Examples from Squaw Creek (Montana, USA) and Lainbach/Schmiedlaine (Upper Bavaria, Germany), Berliner geographische Abhandlungen, Heft 59, Berlin, 229 pp., 1995.

de Roo, A. P. J. and Wesseling, C. G.: LISEM: A single-event physically based hydrological and soil erosion model for drainage basins. I.: Theory, input and output, Hydrol. Process., 10, 11071117, 1996.

Emmett, W. W.: The Hydraulics of Overland Flow On Hillslopes: Dynamic and descriptive studies of hillslopes, Geological survey professional paper, A1-A67, 1970.

Garbrecht, G.: Abflussberechnungen für Flüsse und Kanäle, Die Wasserwirtschaft, 3, 72-77, 1961.

Grottenthaler, W. and Laatsch, W.: Untersuchungen über den Hangabtrag im Lainbachtal bei Benediktbeuern, Forstwirtschaft, 92, 1-19, 1973.

James, M. R. and Robson, S.: Straightforward reconstruction of 3D surfaces and topography with a camera: Accuracy and geoscience application, J. Geophys. Res., 117, 1-17, doi:10.1029/2011JF002289, 2012.

Kaiser, A., Neugirg, F., Rock, G., Müller, C., Haas, F., Ries, J., and Schmidt, J.: Small-Scale Surface Reconstruction and Volume Calculation of Soil Erosion in Complex Moroccan Gully Morphology Using Structure from Motion, Remote Sensing, 6, 7050-7080, doi:10.3390/rs6087050, 2014.
Kaiser, A., Neugirg, F., Schindewolf, M., Haas, F., and Schmidt, J.: Simulation of rainfall effects on sediment transport on steep slopes in an Alpine catchment, Proc. IAHS, 367, 43-50, doi:10.5194/piahs-367-43-2015, 2015.

Laflen, J. M., Lane, L. J., and Foster, G. R.: WEPP - a next generation of erosion prediction technology, J. Soil Water Conserv., 34-38, 1991.

Lowe, D. G.: Object Recognition from Local Scale-Invariant Features, International Conference of Computer Vision, Corfu, 1999.

Michael, A.: Anwendung des physikalisch begründeten Erosionsprognosemodells EROSION 2D/3D - Empirische Ansätze zur Ableitung der Modellparameter, Dissertation, 147 pp., 2000.

Neugirg, F., Kaiser, A., Schmidt, J., Becht, M., and Haas, F.: Quantification, Analysis and Modelling of soil erosion on steep slopes using LiDAR and aerial photographys by an UAV, IAHS Publications, 51-57, 2014.

Nikora, V., Goring, D., and Biggs, B.: On gravelbed roughness characterization, Water Resources Research, 517-527, 1998.

R Development Core Team: A language and environment for statistical computing, Vienna, Austria, R Foundation for Statistical Computing, 2008.

Rahman, M. M., Moran, M. S., Thoma, D. P., Bryant, R., Holifield Collins, C. D., Jackson, T., Orr, B. J., and Tischler, M.: Mapping surface roughness and soil moisture using multi-angle radar imagery without ancillary data, Remote Sens. Environ., 112, 391402, doi:10.1016/j.rse.2006.10.026, 2008.

Schindewolf, M. and Schmidt, J.: Parameterization of the EROSION 2D/3D soil erosion model using a small-scale rainfall simulator and upstream runoff simulation, Catena, 91, 47-55, doi:10.1016/j.catena.2011.01.007, 2012.

Schmidt, J.: A Mathematical Model to Simulate Rainfall Erosion, Erosion, Transport and deposition processes - theories and models, Catena, Supplement, 101-109, 1991.

Schmidt, K. H.: River channel adjustment and sediment budget in response to a catastrophic flood event (Lainbach catchment, Southern Bavaria), Lecture Notes in Earth Sciences, 52, 109_ 127, 1994.

Smith, M. J., Asal, F. F. F., and Priestnal, G.: The use of photogrammetry and LiDAR for landscape roughness estimation in hydrodynamic roughness studies, Proceedings of International Society for Photogrammetry and Remote Sensing XXth Congress, Istanbul, Turkey, 12-23 July 2004, Vol. XXXV, WG III/8, 2004.

Wetzel, K.-F.: Runoff production processes in small alpine catchments within the unconsolidated Pleistocene sediments of the Lainbach area (Upper Bavaria), Hydrol. Process., 17, 24632483, doi:10.1002/hyp.1254, 2003.

Zheng, Z., He, S., and Wu, F.: Relationship between soil surface roughness and hydraulic roughness coefficient on sloping farmland, Water Science and Engineering, 5, 191-201, 2012. 